\title{
Genetics of Food Intake Self-Regulation in Childhood: Literature Review and Research Opportunities
}

\author{
Myles S. Faith ${ }^{\mathrm{a}}$ Susan Carnell ${ }^{\mathrm{b}}$ Tanja V.E. Kral ${ }^{\mathrm{c}}$ \\ ${ }^{a}$ Department of Nutrition, Gillings School of Global Public Health, University of North Carolina - Chapel Hill, \\ Chapel Hill, N.C., b Department of Psychiatry and Behavioral Sciences, The Johns Hopkins University School of \\ Medicine, Baltimore, Md., and ${ }^{\mathrm{C}}$ Department of Biobehavioral Health Sciences, School of Nursing and Perelman \\ School of Medicine, University of Pennsylvania, Philadelphia, Pa., USA
}

\section{Key Words}

Pediatric obesity · Food intake self-regulation - Eating in the absence of hunger - Eating rate - Caloric compensation . Food responsiveness

\begin{abstract}
Pediatric obesity results from a daily energy imbalance between intake and expenditure, an imbalance potentially as slight as $\sim 30-50 \mathrm{kcal} /$ day (e.g., a few extra sips of cola or bites of a cookie). That an 'energy gap' so small may be so powerful suggests the importance of understanding mechanisms of food intake self-regulation (FISR). This review focuses on 4 behavioral indices of FISR in childhood: (1) eating in the absence of hunger; (2) eating rate; (3) caloric compensation and satiety responsiveness, and (4) food responsiveness. Evidence from pediatric samples around the world indicates that these traits are associated with body mass index, are heritable, and are linked to polymorphisms in the FTO gene. We review these data, also discussing their relevance to practical issues of parental feeding styles, portion sizes, and health literacy and numeracy. Research gaps and opportunities for future investigation are discussed. Multidisci-
\end{abstract}

\section{KARGER}

E-Mail karger@karger.com

www.karger.com/hhe plinary approaches and study designs that can address gene-environment interactions are needed to advance the science of FISR and stimulate new avenues for childhood obesity prevention.

(c) 2013 S. Karger AG, Base

\section{Introduction}

Childhood obesity results from an energy imbalance, that is, total energy intake exceeding total expenditure. What is less obvious, if not surprising, to many health professionals is that the daily 'energy gap' leading to childhood obesity onset can be strikingly small. In early childhood ( $\sim 2-5$ years of age), a sustained positive energy balance as slight as $\sim 30-50 \mathrm{kcal} /$ day may promote obesity $[1,2]$. This theoretically could be achieved with only a few extra sips of cola or bites of a cookie. Although other research [3] estimates a higher energy gap (i.e., 110$165 \mathrm{kcal} /$ day), daily binges and 'voracious' overeating do not appear to drive obesity onset for most young children. That the daily energy gap is so subtle underscores the importance of understanding how children self-regulate (c) 2013 S. Karger AG, Basel

$0001-5652 / 13 / 0754-0080 \$ 38.00 / 0$
Myles S. Faith

Department of Nutrition, Gillings School of Global Public Health

University of North Carolina - Chapel Hill, 2204 McGavran-Greenberg Hall, CB 7461 Chapel Hill, NC 27599-7461 (USA)

E-Mail mfaith@unc.edu 
food intake. This question is significant given the prevalence of pediatric obesity in the United States [4] as well as around the world [5-7].

The aim of this paper is to present evidence for genetic influences on food intake self-regulation (FISR) in childhood. We focus on 4 behavioral indices of FISR: (1) eating in the absence of hunger (EAH); (2) eating rate; (3) caloric compensation and satiety responsiveness, and (4) food responsiveness. As described below, these traits have been reliably linked to childhood obesity and/or obesity risk. This paper is organized into four parts. First, we define each FISR behavior and review evidence for genetic influence. Specifically, we summarize evidence for (i) phenotypic associations between that behavior and child weight status, (ii) familial correlations for and heritability of the behavior, and (iii) genetic associations. Such a cascade of evidence, when present, supports the notion of genetic influences on eating behavior $[8,9]$. Although this is an emerging scientific field, we conclude that existing evidence generally supports genetic influences on these traits. The magnitude of genetic influence, though, may depend on measurement issues and other study or sample characteristics (e.g., age and development) that should be examined in future research. Second, we summarize parental feeding practices that might disrupt FISR, including provision of large portion sizes. Then, we tie the present discussion to the broader issue of health literacy and numeracy, in particular, the public's knowledge of genetics concepts and why this is important. In the final section, we highlight a number of exciting research opportunities in this domain.

With respect to molecular genetics findings, we focus primarily on evidence relating to common variants of the fat mass and obesity-associated (FTO) gene, for which there is most evidence for a role in FISR in children, as well as on the melanocortin-4 receptor (MC4R) gene, for which there are also a number of studies. FTO was the first gene to be associated with body mass index (BMI) in large genome-wide association studies (GWAS) [10, 11]; its high-risk allele has been estimated to be present in $42 \%$ of individuals, with each additional risk allele accompanied by a 0.39 increase in BMI [12]. Weight-associated variants of MC4R were revealed in subsequent GWAS [12]. Studies of children and adults have since revealed that FTO and MC4R are associated with differences in weight status [13]. Although little is known about the specific mechanisms by which these genetic variants affect weight, expression is high in the brain [14] and particularly in the hypothalamus [15-17]. This is consistent with the fact that these genes are playing a role in appetite and food intake.

Genetics of FISR in Childhood
We do not focus on other specific obesity genes in this review. Also, we do not address the genetics of food and taste preferences, which are different phenotypes from FISR, even though there is important genetics research being conducted on these topics with children [18-20].

\section{Food Intake Self-Regulation Indexes}

\section{Eating in the Absence of Hunger}

Definition and Measurement

EAH refers to children's tendency to eat in the presence of palatable snack foods despite being satiated [21, $22]$. The behavior is assessed in the laboratory using a 'free-access procedure', during which children have access to a variety of snack foods that they can eat ad libitum; however, this occurs $\sim 15$ min after children have consumed a standardized lunch or dinner to satiety [21, 23]. Foods typically provided during the EAH protocol include chocolate bars, popcorn, pretzels, and other items that are generally low in nutrient density and higher in energy density. These foods are presented as part of a 'play session', in which children are also given the opportunity to read books, play with toys, or engage in other age-appropriate activities. Children can eat as much or little as they desire, with EAH operationalized as total snack intake [typically expressed as calories (kcal) or grams consumed]. Additional details on the assessment of EAH can be found elsewhere [21-23]. A child-report questionnaire measure of EAH has been developed for children [24]. However, the laboratory protocol remains the gold standard.

Phenotypic Association between EAH and Child Weight Status

Children who consume more food in the absence of hunger have a higher BMI and are more likely to be overweight/obese [25]. For example, Fisher and Birch [21] found that girls who showed increased EAH at ages 5 and 7 years were 4.6 times more likely to be obese at both ages compared to girls who showed less EAH at both ages. 'High' versus 'low' scores were based on median splits at each age, specifically, $49 \mathrm{kcal}$ (age 5 years) and $76 \mathrm{kcal}$ (age 7 years) [21]. EAH was associated with a greater BMI zscore and overweight/obesity status (i.e., not overweight/ obese vs. overweight/obese) among adolescents, even when the ad libitum lunch meal preceding the free-access procedure provided multiple food options comprising more than $10,000 \mathrm{kcal}$ [26]. A recent study of 5- to 9-yearold children that invoked an anticipatory laboratory 
stressor (i.e., instructing children to deliver a speech and solve math problems) found that children consumed on average $250 \mathrm{kcal}$ in the absence of hunger, with intakes ranging as high as $700 \mathrm{kcal}$ [27]. Among 8- to 9-year-olds in this study, greater cortisol secretion during the stress induction procedure was associated with greater EAH and higher child BMI. Finally, in two community-based samples of children (7- to 9-year-olds and 9- to 12-yearolds), EAH showed a significant linear association with BMI z-scores in boys but not girls [28]. The authors speculate that this null finding may have been due to social desirability effects inhibiting girls' behavior during the free-access procedure at school. We return to this point below.

\section{Obesity Risk and EAH}

Faith and colleagues [29] compared EAH in two groups of 5-year-old boys and girls, of whom 28 were born at 'high risk' for obesity and 25 at 'low risk'. Children were participants in a prospective birth cohort, the University of Pennsylvania's Infant Growth Study [30], that classified obesity risk based on the maternal pre-pregnancy BMI [31]. In this study, high-risk compared to low-risk boys consumed twice as much energy in the absence of hunger. There was no risk group difference among girls, for whom greater EAH was marginally associated with greater limitations on snack foods at home. Interestingly, in a follow-up of this same cohort at age 13 years, the risk group difference in EAH initially seen among boys was no longer present [32]. Moreover, EAH was significantly greater among low-risk girls compared to high-risk girls, a finding that may have been due to developmental factors such as dieting or social desirability that were not assessed but could have inhibited the snack intake of obeseprone girls.

Family Correlations for and Heritability of EAH

In a sample of 47 same-sex sibling pairs aged 5-12 years, Kral et al. [33] reported a familial association for EAH that was significant among full siblings [intraclass correlation coefficient $($ ICC $)=0.37, \mathrm{p}<0.05$ ] but not half-siblings ( $\mathrm{ICC}=0.16, \mathrm{p}>0.05)$. These results are consistent with genetic influences on the phenotype, although heritability was not formally estimated. Fisher et al. [34] studied 801 children from 300 Hispanic families enrolled in the Viva la Familia Study [35], a study of genetic and environmental influences on behavioral and metabolic phenotypes contributing to childhood obesity onset. EAH was assessed following a laboratory dinner meal that provided more than $50 \%$ of children's estimat- ed daily caloric needs. The results indicated that overweight children consumed $14 \%$ more energy in the absence of hunger compared to nonobese peers. The heritability of EAH was estimated to be $51 \%$.

\section{Genetic Association Studies of EAH}

An association between the FTO genotype and EAH was reported in a British sample of 131 children aged 4-5 years participating in the Twins Early Development Study [36, 37]. EAH was assessed at the participants' homes using a free-access procedure that provided three varieties of (sweet and savory) biscuit snacks to children. The results indicated that children with one or two copies of the A (risk) allele for the FTO polymorphism rs9939609 consumed significantly more biscuits in the absence of hunger compared to children with no risk allele. Specifically, EAH was significantly greater for children with the AA (mean $=39.95 \mathrm{~g}$ ) or AT (mean = $37.93 \mathrm{~g}$ ) genotype compared to children with the TT genotype $($ mean $=30.00 \mathrm{~g})$.

As far as we are aware, no studies have reported associations between the MC4R genotype and EAH. However, one study [38] using 24-hour food recalls demonstrated an association with increased energy intake in children, while another [39] reported an association with greater snacking behavior in children and adolescents. These findings are both consistent with food intake occurring in the absence of deprivation and homeostatic hunger $[40,41]$.

\section{Eating Rate}

Definition and Measurement

The eating rate is operationally defined as total energy (typically kcal) or mouthfuls of food consumed within a given time interval during a laboratory test meal. Thus, the unit of measurement typically is $\mathrm{kcal} / \mathrm{min}$ or bites/ min. Although faster eating could simply result in the same amount of food being consumed in a shorter period, it tends to be associated with greater intake [42], supporting its use as an index of FISR. As noted below, some studies have used parent-report measures to assess the child's eating rate, although the laboratory methodology is considered the gold standard.

\section{Phenotypic Association between Eating Rate and} Childhood Obesity

Rapid eating has been associated with increased adiposity among young children whose eating was directly observed in preschool settings [43,44]. Waxman and Stunkard [45] reported that obese brothers had a faster
Faith/Carnell/Kral 
eating rate than their nonobese siblings at dinner (65.7 vs. $31.7 \mathrm{kcal} / \mathrm{min})$ and lunch (103.5 vs. $46.2 \mathrm{kcal} / \mathrm{min})$. Barkeling et al. [46] used a universal eating monitor to compare the eating behaviors of 23 normal-weight and 20 obese 11-year-old children with respect to total food intake, duration of consumption, rate of eating, and the relative rate of consumption at two lunch meals. They observed that obese children ate faster $(\mathrm{p}<0.05)$ and did not slow their eating rate towards the end of the meal $(\mathrm{p}<$ $0.05)$ compared to normal-weight children. Similar results were reported by Laessle et al. [47]. Lindgren et al. [48] also found a relative lack of deceleration through the meal in obese compared to normal-weight 5- to 18-yearolds. Sugimori et al. [49] studied 8,170 children in the Toyama Birth Cohort study at ages 3 and 6 years. Children were classified in terms of their eating speed, based on parent reports, at both assessment times. Compared to children who were normal-weight at both ages 3 and 6 years (prevalence $=5.7 \%$ ), slightly rapid or rapid eating was significantly greater among children who were normal-weight at age 3 years but became obese at age 6 years (prevalence $=22.6 \%$ ) as well as in children who were obese at both ages 3 and 6 years (prevalence $=26.8 \%$ ). Berkowitz et al. [50] found that a faster eating rate at 4 years of age, expressed as mouthfuls of food/min at a single laboratory test meal, predicted a greater BMI and fat gain in children between ages 4 and 6 years.

\section{Family Correlations for and Heritability of Eating}

Rate

Llewellyn et al. [51] assessed the eating rate (mouthfuls/min) of 254 pairs of twins aged 10-12 years. The children were video-recorded while eating a standard meal at home (i.e., 24 sandwich quarters on two plates plus mixed/ chopped fruit salads). The results indicated that overweight/obese youth had a significantly faster eating rate (bites/min) and total food bites compared to lower normal-weight youth. Biometric analyses revealed a significant heritable component to eating rate, with $62 \%$ of the variance in the phenotype due to additive genetic factors. Interestingly, the same investigators confirmed a heritable component to infant eating rate in a British population-based twin registry, the Gemini study [52]. Gemini is a prospective cohort of 2,042 families with twins born in England and Wales between March and December 2007. The infant eating rate was assessed at 4 months of age by the parent-report Baby Eating Behavior Questionnaire (BEBQ) [53], and biometric analyses revealed that $84 \%$ of the variance in the trait was due to additive genetic factors [54].

Genetics of FISR in Childhood
Genetic Association Studies of Child Eating Rate

We are unaware of any studies reporting an association between specific genes and individual differences in child eating rate.

\section{Caloric Compensation and Satiety Responsiveness}

Definition and Measurement

'Caloric compensation' and 'satiety responsiveness' refer to a similar construct, that is, the ability to recognize and adjust eating in response to internal feelings of fullness or satiety $[55,56]$. Operationally, however, they are measured very differently. Compensation is measured by a laboratory-based preloading paradigm that assesses the children's ability to adjust food intake following a low-versus high-calorie preload (food or beverage). The protocol is based on the assumption that children should eat less food at an ad libitum meal $\sim 20$ min following the higher-compared to the lower-energy preload, an adjustment that reflects 'compensation'. The ability to compensate can be numerically quantified for individual children, with deviation from perfect compensation reflecting poorer self-regulatory eating [5763]. This assessment method is considered the gold standard because it is a direct behavioral measurement obtained under controlled laboratory conditions. Satiety responsiveness, in contrast, is assessed by the parentreport Child Eating Behaviour Questionnaire (CEBQ) [64], with the attendant disadvantage of potential reporting bias by parents. The benefit of this measure, though, is the possibility to characterize the eating behavior of children across a range of situations, rather than behavior in the laboratory on a small number of occasions, which could be vulnerable to situational influences. This questionnaire instructs parents to respond to situations such as 'My child gets full up easily' and 'My child gets full before his/her meal is finished'.

\section{Phenotypic Association between Caloric}

Compensation, Satiety Responsiveness, and Obesity

Several laboratory-based studies have demonstrated poorer compensation in heavier children. Johnson and Birch [65], for example, reported a significant negative association $(\mathrm{r}=-0.37)$ between compensation ability and adiposity in 3- to 5-year-olds, but among girls only, while Birch and Fisher [66] found that compensation predicted the 24-hour energy intake, which in turn predicted the relative weight, in a sample of 4 - to 6-year-old girls. A study of 9- to 14-year-old boys also reported poorer compensation in obese than normal-weight children [67]. We found in two independent samples that poorer compen- 
sation was associated with greater total percent body fat measured by dual energy X-ray absorptiometry, although, interestingly, not with child BMI $[68,69]$.

A number of studies using the CEBQ to assess satiety responsiveness have found that children with a higher BMI or who were overweight/obese had, according to their parents, poorer satiety responsiveness than normalweight children $[65,70-74]$.

Family Correlations for and Heritability of

Compensation and Satiety Responsiveness

Carnell et al. [75] studied 5,435 twin pairs aged 8-11 years whose satiety responsiveness was assessed by the CEBQ [64]. Their results indicated that $63 \%$ of the variance in satiety responsiveness was due to additive genetic factors, with the remaining variance accounted for by environmental factors. In Gemini, the study of infant twins, the heritability of satiety responsiveness was estimated to be even higher (72\%) [54]. Surprisingly, a different conclusion was reached by Faith et al. [68], who assessed compensation using a laboratory-based preloading paradigm $[59,65]$. They studied a sample of 69 same-sex twins aged 4-7 years recruited from the New York metropolitan area. In this investigation, the heritability was estimated to be $0 \%$ (i.e., no genetic influence). The inconsistent findings between this study and others may be due to measurement issues (e.g., parent report vs. laboratory observation), age differences (e.g., 8 years and older and infants vs. $4-7$ years), and/or sample size differences (e.g., hundreds of child participants vs. less than 70). We return to this point in the Conclusions section.

In a sample of weight-discordant siblings aged 5-12 years, Kral et al. [33] reported a familial association for $\%$ COMPX that was significant among full siblings (ICC $=0.36, \mathrm{p}<0.05)$ but not half-siblings (ICC $=0.02$, $\mathrm{p}>0.05$ ). Again, these results are consistent with genetic influences on the \%COMPX phenotype, although heritability was not formally estimated.

Genetic Association Studies of Compensation and

Satiety Responsiveness

An association between the FTO genotype and child satiety responsiveness, as assessed by the CEBQ, was reported in a study of 3,337 children aged 8-11 years [76]. Specifically, responsiveness to internal fullness cues was significantly poorer for children with the AA genotype $($ mean $=2.55)$ compared to the AT $($ mean $=2.65)$ and TT genotypes $($ mean $=2.67)(p=0.008)$. Moreover, mediator analyses confirmed that satiety responsiveness par- tially mediated the association between the FTO genotype and child BMI z-score. A more recent study [77] using the CEBQ additionally reported an association between the MC4R genotype and this CEBQ scale, such that the risk variant was associated with lower satiety responsiveness scores in a community sample of obese children. Similarly, Cecil et al. [78] found that total energy intake at a school lunch test meal was significantly greater among 4- to 10-year-old children carrying the $\mathrm{A}$ (risk) allele compared to children not carrying the A allele.

\section{Food Responsiveness}

Definition and Measurement

Food responsiveness refers to the tendency to eat in response to food cues $[56,71]$. That is, certain children are more responsive than others to the presence (e.g., sight and smell) of foods in the environment. This construct is based on classical experiments by Schachter and colleagues [79-81] and subsequent work by Wardle and colleagues [55, 56, 71, 73, 82-84]. Child food responsiveness has been assessed by the CEBQ [64] as well as with the external eating scale of the Dutch Eating Behaviour Questionnaire (DEBQ [85]), which is available in both a child-report (DEBQ-C [86]) and parent-report form (DEBQ-P [87]).

\section{Phenotypic Association between Food}

Responsiveness and Obesity

In a report of 572 children aged 3-5 years recruited from a British community sample, greater food responsiveness assessed by the CEBQ was associated with a higher BMI $z$-score $(r=0.18, p<0.001)$ [71]. In a sample of 294 Chilean children aged 6-12 years, food responsiveness was significantly greater among obese compared to normal-weight boys and girls [88]. In another cross-sectional investigation of 6- to 7-year-old youth residing in the Netherlands, greater food responsiveness was associated with higher BMI $\mathrm{z}$-scores in multiple regression models that adjusted for child sex and age, parental education, and parental employment status [89]. Evidence using the DEBQ is more mixed, with some evidence suggesting higher scores in obese children [87], but other evidence suggesting a negative association $[90,91]$ or no relationship [92]. This variance in results is likely because the CEBQ aims to capture the normal range of eating styles, while the DEBQ is designed to assess disordered eating behavior.
Faith/Carnell/Kral 
Familial Associations for and Heritability of Food

Responsiveness

Carnell et al. [75] reported that $72 \%$ of the variance in a measure of food cue responsiveness (CEBQ enjoyment of food scale) was due to additive genetic factors in a sample of several thousand twin pairs assessed at 8-11 years of age, while analyses of the Gemini cohort reported 59\% heritability in BEBQ food responsiveness scores for infants, suggesting that this particular measure of FISR may show more environmental influence early in life [54].

Genetic Association Studies of Food Responsiveness

An association between food responsiveness and the FTO genotype has been recently reported in an analysis of 1,718 children of European descent enrolled in the Generation R study [93], a population-based cohort of fetal life onwards in the city of Rotterdam, the Netherlands. Velders et al. [94] found that, at age 4 years, children with the A (risk) allele at rs9939609 were significantly more likely to be high in food responsiveness as assessed by the CEBQ compared to children without the A allele. We are not aware of any reports of significant associations between the MC4R genotype and the CEBQ food responsiveness scale. However, the study by Valladares et al. [77] revealed a positive association with the CEBQ enjoyment of food scale, such that the risk variant was associated with higher scores.

\section{Parental Feeding Styles, Food Portioning, and FISR}

Parents are key 'gate-keepers' of the home food environment, especially for young children. They determine which foods come into the home and interact with children during meals. To this end, it is important to know whether certain parental feeding practices promote poorer FISR and/or contribute to childhood obesity by disrupting FISR. There is consistent evidence that 'restrictive' feeding by parents (i.e., limiting access to palatable, typically high-fat high-sugar foods) is associated with poorer compensation and greater EAH $[23,95,96]$. The association appears to be bidirectional, although experimental research supports the hypothesis that restricting access to foods leads to greater intake of those foods when children have subsequent access [96]. 'Indulgent' parenting practices have also been linked to childhood obesity [97]. It is conceivable that genetic influences on child FISR are moderated by (i.e., exacerbated or protected by) specific feeding styles, although data on this topic are lacking. This represents a great opportunity for research

Genetics of FISR in Childhood given the current interest in epigenetic pathways leading to obesity [98].

Parents also play a role in determining the portion size of foods served to their children. This is important because portion size is a strong determinant of energy intake in adults [99-103] and children [104-108]. To date, few individual differences have been identified with respect to children's susceptibility to overeating when served large food portions. Some evidence suggests that overweight and obese children may be more vulnerable to overeating than normal-weight children when presented with large food portions. For example, when the portion size of three fruit and vegetable side dishes was doubled at a meal, Kral et al. [109] demonstrated that overweight and obese children showed an almost three times greater increase in intake of those foods compared to normal-weight children. Similarly, data from two recent laboratory studies also indicate that obese children, in particular, may be more susceptible to overeating when served large portions of palatable energy-dense foods $[110,111]$. Whether genes for FISR influence children's responsiveness to large food portions remains to be seen.

To the extent that certain parenting behaviors disrupt children's FISR, there might be advantages to having children self-serve food portions. Indeed, Fisher et al. [112] showed that children with a tendency to 'overconsume' when served large food portions reduced their meal energy intake by $11 \%$ when allowed to self-serve themselves than when the portion was served to them. The beneficial effect on intake of having children self-determine their food portions, however, has not been consistent across studies [113] and may be influenced by external eating cues [114].

\section{Health Literacy, Numeracy, and Genetics of FISR}

The present review should be considered in the broader context of discussions on health literacy and numeracy, the public's understanding of genetics, and how this broader knowledge potentially could promote healthier eating. There is a growing field of health literacy and numeracy specifically as they relate to genetics information, concepts, and the potential for motivating behavioral changes [115-118]. Data are limited but increasing [119]. Interestingly, a Cochrane literature review examined the impact of communicating DNA-based disease risk estimates on the motivation for behavioral changes [120]. The results indicated that genetics feedback had no impact on smoking or physical activity but a significant ef- 
fect on self-reported diet. It is possible that providing information on genetic risk and eating regulation to some individuals, in the broader context of obesity, might promote healthier eating. Randomized controlled clinical trials [e.g., 121] are needed to answer this question.

\section{Conclusions and Research Opportunities}

The studies presented in this review, taken together and when reviewed as a 'cascade' of evidence [9], support the notion that genes influence children's capacity to selfregulate food intake. The emerging picture is one of nature and nurture, with molecular genetic associations only beginning to be discovered. The 4 traits examined in this report, on balance, are associated with variations in overweight status. Moreover, evidence from the larger twin studies across the age spectrum suggests sizable heritable influences. That said, there are important caveats to this conclusion that are relevant for the design of future studies. First, FISR traits can be measured via direct observation or parent reports, and findings from these methods do not necessarily converge $[75,122]$. Each approach has virtues and disadvantages and, ideally, multiple measurement strategies should be used to establish convergent findings. Second, social desirability may have an impact on the assessment of FISR, especially when directly measuring food intake. For example, older girls may be inclined suppress eating during the free-access protocol of the EAH assessment [28, 32], which may affect the internal validity of genetics studies. Future studies should be mindful of this potential drawback and should attempt to manage or minimize these influences, if possible, especially with older children. Third, there may be age-specific genetic influences on FISR traits, an issue that, to our knowledge, has not been formally tested yet. This is possible as genetic influences on BMI increase during childhood [123]. Fourth, of the few genetic association studies published to date, all have used a candidate gene strategy focusing on FTO rather than examining multiple genes or genetic profile scores. This latter approach may prove fruitful in future studies.

At present, the genetics of FISR is a relatively young research field, and many exciting questions remain to be addressed. Questions to explore include:

- To what extent are the aspects of FISR that we have discussed distinct conceptually and/or biologically? Is it scientifically helpful to separate them and probe the etiology of each, or are they all imperfect measures of the same underlying biobehavioral phenomenon?
- To what extent do gene-environment interactions exist, such that genetic influences on FISR are amplified or suppressed depending on environmental factors known to influence food intake (e.g., large vs. small portion sizes, variety)?

- To what extent do epigenetic factors during pregnancy/infancy impact FISR traits? For example, how do maternal dietary patterns during pregnancy influence infants' food responsiveness or satiety responsiveness?

- To what extent do parenting styles (e.g., restrictive or indulgent feeding) moderate genetic influences on FISR? Do interactions between parent behaviors and specific genes exist?

- To what extent do genetic influences on FISR influence children's general self-control and self-regulation? Are these traits correlated or orthogonal? To what extent do they share common genetic underlying pathways?

- To what extent do cultural and social norms mitigate genetic influences on FISR?

- How can the information presented in this literature be used to guide pediatric obesity treatment and prevention efforts? For example, would parents behave differently if they knew that their child had a genetic predisposition to eat in response to food cues? How else might this information guide novel interventions, if at all?

Developing and answering these questions will require multidisciplinary collaborations, careful choice of behavioral, environmental, genetic, and biological assessments as well as samples that are large and variable enough to achieve adequate power to examine gene-environment interactions. Such efforts promise not only to advance the science of FISR but to stimulate new approaches to obesity prevention and treatment.

References

$\checkmark 1$ Goran MI: Metabolic precursors and effects of obesity in children: a decade of progress, 1990-1999. Am J Clin Nutr 2001;73:158171.

-2 Sun M, Gower BA, Bartolucci AA, Hunter GR, Figueroa-Colon R, Goran MI: A longitudinal study of resting energy expenditure relative to body composition during puberty in African American and white children. Am J Clin Nutr 2001;73:308-315.

-3 Wang YC, Gortmaker SL, Sobol AM, Kuntz KM: Estimating the energy gap among US children: a counterfactual approach. Pediatrics 2006;118:e1721-e1733.
Faith/Carnell/Kral 
-4 Hedley AA, Ogden CL, Johnson CL, Carroll MD, Curtin LR, Flegal KM: Prevalence of overweight and obesity among US children, adolescents, and adults, 1999-2002. JAMA 2004;291:2847-2850.

5 Lobstein T: The prevention of obesity in children. Pediatr Endocrinol Rev 2004;1(suppl 3):471-475

6 Lobstein T, Baur L, Uauy R: Obesity in children and young people: a crisis in public health. Obes Rev 2004;5(suppl 1):4-104.

7 Lobstein T, Baur LA: Policies to prevent childhood obesity in the European Union. Eur J Public Health 2005;15:576-579.

8 Kral TV, Faith MS: Child eating patterns and weight regulation: a developmental behaviour genetics framework. Acta Paediatr Suppl 2007;96:29-34.

9 Faith MS: Behavioral science and the study of gene-nutrition and gene-physical activity interactions in obesity research. Obesity (Silver Spring) 2008;16(suppl 3):S82-S84.

10 Frayling TM, Timpson NJ, Weedon MN, et al: A common variant in the FTO gene is associated with body mass index and predisposes to childhood and adult obesity. Science 2007; 316:889-894.

11 Scuteri A, Sanna S, Chen WM, et al: Genomewide association scan shows genetic variants in the FTO gene are associated with obesityrelated traits. PLoS Genet 2007;3:e115.

12 Speliotes EK, Willer CJ, Berndt SI, et al: Association analyses of 249,796 individuals reveal 18 new loci associated with body mass index. Nat Genet 2010;42:937-948.

13 den Hoed M, Ekelund U, Brage S, et al: Genetic susceptibility to obesity and related traits in childhood and adolescence: influence of loci identified by genome-wide association studies. Diabetes 2010;59:2980-2988.

14 Willer CJ, Speliotes EK, Loos RJ, et al: Six new loci associated with body mass index highlight a neuronal influence on body weight regulation. Nat Genet 2009;41:25-34.

15 Dina C, Meyre D, Gallina S, et al: Variation in FTO contributes to childhood obesity and severe adult obesity. Nat Genet 2007;39:724726

16 Gerken T, Girard CA, Tung YC, et al: The obesity-associated FTO gene encodes a 2-oxoglutarate-dependent nucleic acid demethylase. Science 2007;318:1469-1472.

17 Tung YC, Ayuso E, Shan X, et al: Hypothalamic-specific manipulation of Fto, the ortho$\log$ of the human obesity gene FTO, affects food intake in rats. PloS One 2010;5:e8771.

-18 Burd C, Senerat A, Chambers E, Keller KL: PROP taster status interacts with the built environment to influence children's food acceptance and body weight status. Obesity (Silver Spring) 2013;21:786-794.

19 Keller KL: Genetic influences on oral fat perception and preference: presented at the symposium 'The Taste for Fat: New Discoveries on the Role of Fat in Sensory Perception, Metabolism, Sensory Pleasure and Beyond' held at the Institute of Food Technologists 2011
Annual Meeting, New Orleans, LA, June 12, 2011. J Food Sci 2012;77:S143-S147.

20 Keller KL, Steinmann L, Nurse RJ, Tepper BJ: Genetic taste sensitivity to 6-n-propylthiouracil influences food preference and reported intake in preschool children. Appetite 2002;38:3-12.

21 Fisher JO, Birch LL: Eating in the absence of hunger and overweight in girls from 5 to $7 \mathrm{y}$ of age. Am J Clin Nutr 2002;76:226-231.

22 Fisher JO, Birch LL: Restricting access to foods and children's eating. Appetite 1999;32: 405-419.

23 Birch LL, Fisher JO, Davison KK: Learning to overeat: maternal use of restrictive feeding practices promotes girls' eating in the $\mathrm{ab}$ sence of hunger. Am J Clin Nutr 2003;78: 215-220.

24 Tanofsky-Kraff M, Ranzenhofer LM, Yanovski SZ, et al: Psychometric properties of a new questionnaire to assess eating in the absence of hunger in children and adolescents. Appetite 2008;51:148-155.

25 Kral TV, Faith MS: Influences on child eating and weight development from a behavioral genetics perspective. J Pediatr Psychol 2009; 34:596-605.

26 Shomaker LB, Tanofsky-Kraff M, Zocca JM, et al: Eating in the absence of hunger in adolescents: intake after a large-array meal compared with that after a standardized meal. Am J Clin Nutr 2010;92:697-703.

27 Francis LA, Granger DA, Susman EJ: Adrenocortical regulation, eating in the absence of hunger and BMI in young children. Appetite 2012;64C:32-38

28 Hill C, Llewellyn CH, Saxton J, et al: Adiposity and 'eating in the absence of hunger' in children. Int J Obes (Lond) 2008;32:14991505.

29 Heo M, Pietrobelli A, Fontaine KR, Sirey JA, Faith MS: Depressive mood and obesity in US adults: comparison and moderation by sex, age, and race. Int J Obes (Lond) 2006;30:513519.

30 Stunkard AJ, Berkowitz RI, Stallings VA, Schoeller DA: Energy intake, not energy output, is a determinant of body size in infants. Am J Clin Nutr 1999;69:524-530.

31 Whitaker RC, Wright JA, Pepe MS, Seidel KD, Dietz WH: Predicting obesity in young adulthood from childhood and parental obesity. N Engl J Med 1997;337:869-873.

32 Kral TV, Moore RH, Stunkard AJ, et al: Adolescent eating in the absence of hunger and relation to discretionary calorie allowance. J AM Diet Assoc 2010;110:1896-1900.

33 Kral TV, Allison DB, Birch LL, Stallings VA, Moore RH, Faith MS: Caloric compensation and eating in the absence of hunger in 5- to 12-years-old weight-discordant siblings. Am J Clin Nutr 2012;96:574-583.

34 Fisher JO, Cai G, Jaramillo SJ, Cole SA, Comuzzie AG, Butte NF: Heritability of hyperphagic eating behavior and appetite-related hormones among Hispanic children. Obesity (Silver Spring) 2007;15:1484-1495.
5 Butte NF, Cai G, Cole SA, et al: Metabolic and behavioral predictors of weight gain in Hispanic children: the Viva la Familia Study. Am J Clin Nutr 2007;85:1478-1485.

36 Haworth CM, Davis OS, Plomin R: Twins Early Development Study (TEDS): a genetically sensitive investigation of cognitive and behavioral development from childhood to young adulthood. Twin Res Hum Genet 2013; 16:117-125.

37 Trouton A, Spinath FM, Plomin R: Twins Early Development Study (TEDS): a multivariate, longitudinal genetic investigation of language, cognition and behavior problems in childhood. Twin Res 2002;5:444-448.

38 Cole SA, Butte NF, Voruganti VS, et al: Evidence that multiple genetic variants of MC4R play a functional role in the regulation of energy expenditure and appetite in Hispanic children. Am J Clin Nutr 2010;91:191-199.

-39 Stutzmann F, Cauchi S, Durand E, et al: Common genetic variation near MC4R is associated with eating behaviour patterns in European populations. Int J Obes (Lond) 2009;33: 373-378.

40 Blundell JE, Finlayson G: Is susceptibility to weight gain characterized by homeostatic or hedonic risk factors for overconsumption? Physiol Behav 2004;82:21-25.

41 Lutter M, Nestler EJ: Homeostatic and hedonic signals interact in the regulation of food intake. J Nutr 2009;139:629-632.

42 Kaplan DL: Eating style of obese and nonobese males. Psychosom Med 1980;42:529538.

43 Drabman RS, Hammer D, Jarvie GJ: Eating styles of obese and nonobese black and white children in a naturalistic setting. Addict Behav 1977;2:83-86.

-44 Drabman RS, Cordua GD, Hammer D, Jarvie GJ, Horton W: Developmental trends in eating rates of normal and overweight preschool children. Child Dev 1979;50:211-216.

45 Waxman M, Stunkard AJ: Caloric intake and expenditure of obese boys. J Pediatr 1980;96: 187-193.

46 Barkeling B, Ekman S, Rossner S: Eating behaviour in obese and normal weight 11-yearold children. Int J Obes Relat Metab Disord 1992;16:355-360

47 Laessle RG, Uhl H, Lindel B, Muller A: Parental influences on laboratory eating behavior in obese and non-obese children. Int J Obes Relat Metab Disord 2001;25(suppl 1):S60-S62.

48 Lindgren AC, Barkeling B, Hagg A, Ritzen EM, Marcus C, Rossner S: Eating behavior in Prader-Willi syndrome, normal weight, and obese control groups. J Pediatr 2000;137:50-55.

49 Sugimori H, Yoshida K, Izuno T, et al: Analysis of factors that influence body mass index from ages 3 to 6 years: a study based on the Toyama cohort study. Pediatr Int 2004;46:302-310.

50 Berkowitz RI, Moore RH, Faith MS, Stallings VA, Kral TV, Stunkard AJ: Identification of an obese eating style in 4-year-old children born at high and low risk for obesity. Obesity (Silver Spring) 2010;18:505-512. 
51 Llewellyn $\mathrm{CH}$, van Jaarsveld CH, Boniface D, Carnell S, Wardle J: Eating rate is a heritable phenotype related to weight in children. Am J Clin Nutr 2008;88:1560-1566.

52 van Jaarsveld CH, Johnson L, Llewellyn C, Wardle J: Gemini: a UK twin birth cohort with a focus on early childhood weight trajectories, appetite and the family environment. Twin Res Hum Genet 2010;13:72-78.

53 Llewellyn $\mathrm{CH}$, van Jaarsveld $\mathrm{CH}$, Johnson L, Carnell S, Wardle J: Development and factor structure of the Baby Eating Behaviour Questionnaire in the Gemini birth cohort. Appetite 2011;57:388-396.

- 54 Llewellyn $\mathrm{CH}$, van Jaarsveld $\mathrm{CH}$, Johnson L, Carnell S, Wardle J: Nature and nurture in infant appetite: analysis of the Gemini twin birth cohort. Am J Clin Nutr 2010;91:11721179.

55 Carnell S, Wardle J: Appetitive traits in children. New evidence for associations with weight and a common, obesity-associated genetic variant. Appetite 2009;53:260-263.

-56 Carnell S, Wardle J: Appetitive traits and child obesity: measurement, origins and implications for intervention. Proc Nutr Soc 2008; 67: 343-355.

57 Birch LL: Acquisition of food preferences and eating patterns in children; in Fairburn CG, Brownell KD (eds): Eating Disorders and Obesity, ed 2. New York, Guilford Press, 2002, pp 75-79.

58 Birch LL: The role of experience in children's food acceptance patterns. J Am Diet Assoc 1987;87:S36-S40.

-59 Birch LL, Birch D, Marlin DW, Kramer L: Effects of instrumental consumption on children's food preference. Appetite 1982;3:125134.

60 Birch LL, Davison KK: Family environmental factors influencing the developing behavioral controls of food intake and childhood overweight. Pediatr Clin North Am 2001;48:893907.

61 Birch LL, Deysher M: Caloric compensation and sensory specific satiety: evidence for self regulation of food intake by young children. Appetite 1986;7:323-331.

62 Birch LL, Deysher M: Conditioned and unconditioned caloric compensation: evidence for self-regulation of food intake by young children. Learn Motiv 1985;16:341-355.

63 Birch LL, Fisher JA: Appetite and eating behavior in children. Pediatr Clin North Am 1995;42:931-953.

64 Wardle J, Guthrie CA, Sanderson S, Rapoport L: Development of the Children's Eating Behaviour Questionnaire. J Child Psychol Psychiatry 2001;42:963-970.

65 Johnson SL, Birch LL: Parents' and children's adiposity and eating style. Pediatrics 1994;94: 653-661.

-66 Birch LL, Fisher JO: Mothers' child-feeding practices influence daughters' eating and weight. Am J Clin Nutr 2000;71:1054-1061.

-67 Bellissimo N, Desantadina MV, Pencharz PB, Berall GB, Thomas SG, Anderson GH: A comparison of short-term appetite and energy intakes in normal weight and obese boys following glucose and whey-protein drinks. Int J Obes (Lond) 2008;32:362-371.

68 Faith MS, Pietrobelli A, Heo M, et al: A twin study of self-regulatory eating in early childhood: estimates of genetic and environmental influence, and measurement considerations. Int J Obes (Lond) 2012;36:931-937.

69 Kral TV, Allison DB, Birch LL, Stallings VA, Moore RH, Faith MS: Caloric compensation and eating in the absence of hunger in 5- to 12 -year-old weight-discordant siblings. Am J Clin Nutr 2012;96:574-583.

70 Jansen PW, Roza SJ, Jaddoe VW, et al: Children's eating behavior, feeding practices of parents and weight problems in early childhood: results from the population-based Generation R Study. Int J Behav Nutr Phys Act 2012;9:130.

71 Carnell S, Wardle J: Appetite and adiposity in children: evidence for a behavioral susceptibility theory of obesity. Am J Clin Nutr 2008; 88:22-29.

72 Viana V, Sinde S, Saxton JC: Children's Eating Behaviour Questionnaire: associations with BMI in Portuguese children. Br J Nutr 2008; 100:445-450.

73 Webber L, Hill C, Saxton J, Van Jaarsveld CH, Wardle J: Eating behaviour and weight in children. Int J Obes (Lond) 2009;33:21-28.

74 Spence JC, Carson V, Casey L, Boule N: Examining behavioural susceptibility to obesity among Canadian pre-school children: the role of eating behaviours. Int J Pediatr Obes 2011;6:e501-e507.

75 Carnell S, Haworth CM, Plomin R, Wardle J: Genetic influence on appetite in children. Int J Obes (Lond) 2008;32:1468-1473.

76 Wardle J, Carnell S, Haworth CM, Farooqi IS, O’Rahilly S, Plomin R: Obesity associated genetic variation in FTO is associated with diminished satiety. J Clin Endocrinol Metab 2008;93:3640-3643.

77 Valladares M, Dominguez-Vasquez P, Obregon AM, et al: Melanocortin-4 receptor gene variants in Chilean families: association with childhood obesity and eating behavior. Nutr Neurosci 2010;13:71-78.

78 Cecil JE, Tavendale R, Watt P, Hetherington MM, Palmer CN: An obesity-associated FTO gene variant and increased energy intake in children. N Engl J Med 2008:359:2558-2566.

79 Schachter S: Some extraordinary facts about obese humans and rats. Am Psychol 1971;26: 129-144.

80 Schachter S: Obesity and eating. Internal and external cues differentially affect the eating behavior of obese and normal subjects. Science 1968;161:751-756.

81 Schachter S, Goldman R, Gordon A: Effects of fear, food deprivation, and obesity on eating. J Pers Soc Psychol 1968;10:91-97.

82 Carnell S, Wardle J: Measuring behavioural susceptibility to obesity: validation of the child eating behaviour questionnaire. Appetite 2007;48:104-113.
83 Koeppen-Schomerus G, Wardle J, Plomin R: A genetic analysis of weight and overweight in 4 -year-old twin pairs. Int J Obes Relat Metab Disord 2001;25:838-844.

84 Wardle J, Llewellyn C, Sanderson S, Plomin $\mathrm{R}$ : The FTO gene and measured food intake in children. Int J Obes (Lond) 2009;33:42-45.

85 van Strien T, Frijters JE, Bergers GP, Defares PB: The Dutch Eating Behavior Questionnaire (DEBQ) for assessment of restrained, emotional, emotional, and external eating behavior. Int J Eat Disord 1986;5:295-315.

86 van Strien T, Oosterveld P: The children's DEBQ for assessment of restrained, emotion$\mathrm{al}$, and external eating in 7- to 12-year-old children. Int J Eat Disord 2008;41:72-81.

87 Braet C, Van Strien T: Assessment of emotional, externally induced and restrained eating behaviour in nine to twelve-year-old obese and non-obese children. Behav Res Ther 1997;35:863-873.

88 Santos JL, Ho-Urriola JA, Gonzalez A, et al: Association between eating behavior scores and obesity in Chilean children. Nutr J 2011; 10:108.

89 Sleddens EF, Kremers SP, Thijs C: The Children's Eating Behaviour Questionnaire: factorial validity and association with Body Mass Index in Dutch children aged 6-7. Int J Behav Nutr Phys Act 2008;5:49.

90 Ledoux T, Watson K, Baranowski J, Tepper BJ, Baranowski T: Overeating styles and adiposity among multiethnic youth. Appetite 2011;56:71-77.

-91 Banos RM, Cebolla A, Etchemendy E, Felipe S, Rasal P, Botella C: Validation of the Dutch Eating Behavior Questionnaire for Children (DEBQ-C) for use with Spanish children. Nutr Hosp 2011;26:890-898.

92 Caccialanza R, Nicholls D, Cena H, et al: Validation of the Dutch Eating Behaviour Questionnaire parent version (DEBQ-P) in the Italian population: a screening tool to detect differences in eating behaviour among obese, overweight and normal-weight preadolescents. Eur J Clin Nutr 2004;58:1217-1222.

93 Tiemeier H, Velders FP, Szekely E, et al: The Generation R Study: a review of design, findings to date, and a study of the 5-HTTLPR by environmental interaction from fetal life onward. J Am Acad Child Adolesc Psychiatry 2012;51:1119.e7-1135.e7.

94 Velders FP, De Wit JE, Jansen PW, et al: FTO at rs9939609, food responsiveness, emotional control and symptoms of ADHD in preschool children. PloS One 2012;7:e49131.

95 Faith MS, Scanlon KS, Birch LL, Francis LA, Sherry B: Parent-child feeding strategies and their relationships to child eating and weight status. Obes Res 2004;12:1711-1722.

96 Ventura AK, Birch LL: Does parenting affect children's eating and weight status? Int J Behav Nutr Phys Act 2008;5:15.

97 Hughes SO, Shewchuk RM, Baskin ML, Nicklas TA, Qu H: Indulgent feeding style and children's weight status in preschool. J Dev Behav Pediatr 2008;29:403-410. 
\$98 Wu Q, Suzuki M: Parental obesity and overweight affect the body-fat accumulation in the offspring: the possible effect of a high-fat diet through epigenetic inheritance. Obes Rev 2006;7:201-208.

$\checkmark 99$ Kral TV, Rolls BJ: Energy density and portion size: their independent and combined effects on energy intake. Physiol Behav 2004; 82:131-138.

100 Rolls BJ, Morris EL, Roe LS: Portion size of food affects energy intake in normal-weight and overweight men and women. Am J Clin Nutr 2002;76:1207-1213.

101 Rolls BJ, Roe LS, Kral TV, Meengs JS, Wall DE: Increasing the portion size of a packaged snack increases energy intake in men and women. Appetite 2004;42:63-69.

-102 Diliberti N, Bordi PL, Conklin MT, Roe LS, Rolls BJ: Increased portion size leads to increased energy intake in a restaurant meal. Obes Res 2004;12:562-568.

103 Rolls BJ: The supersizing of America: portion size and the obesity epidemic. Nutr Today 2003;38:42-53.

104 Fisher JO, Kral TV: Super-size me: portion size effects on young children's eating. Physiol Behav 2008;94:39-47.

105 Fisher JO, Arreola A, Birch LL, Rolls BJ: Portion size effects on daily energy intake in low-income Hispanic and African American children and their mothers. Am J Clin Nutr 2007;86:1709-1716.

>106 Rolls BJ, Engell D, Birch LL: Serving portion size influences 5-year-old but not 3-year-old children's food intakes. J Am Diet Assoc 2000;100:232-234.
107 Fisher JO: Effects of age on children's intake of large and self-selected food portions. Obesity (Silver Spring) 2007;15:403-412.

108 Fisher JO, Liu Y, Birch LL, Rolls BJ: Effects of portion size and energy density on young children's intake at a meal. Am J Clin Nutr 2007;86:174-179.

109 Kral TV, Kabay AC, Roe LS, Rolls BJ: Effects of doubling the portion size of fruit and vegetable side dishes on children's intake at a meal. Obesity (Silver Spring) 2010;18:521527.

110 Fisher JO, Zakeri I, Birch LL, Kral TV: Individual differences in susceptibility to large portion sizes among obese and non-obese African American children. The Obesity Society Meeting, San Antonio, 2012.

111 Kral TV, Remiker AM, Rauh EM, Moore $\mathrm{RH}$ : Role of child weight status and the relative reinforcing value of food in children's responsiveness to portion size increases. Under review.

112 Fisher JO, Rolls BJ, Birch LL: Children’s bite size and intake of an entree are greater with large portions than with age-appropriate or self-selected portions. Am J Clin Nutr 2003; 77:1164-1170.

113 Savage JS, Haisfield L, Fisher JO, Marini M, Birch LL: Do children eat less at meals when allowed to serve themselves? Am J Clin Nutr 2012;96:36-43.

114 Fisher JO, Birch LL, Zhang J, Grusak MA, Hughes SO: External influences on children's self-served portions at meals. Int J Obes (Lond) 2013, E-pub ahead of print.

-115 Lea DH, Kaphingst KA, Bowen D, Lipkus I, Hadley DW: Communicating genetic and genomic information: health literacy and numeracy considerations. Public Health Genomics 2011;14:279-289.
16 Wang C, Bowen DJ, Kardia SL: Research and practice opportunities at the intersection of health education, health behavior, and genomics. Health Educ Behav 2005;32:686701.

117 McBride CM, Alford SH, Reid RJ, Larson EB, Baxevanis AD, Brody LC: Putting science over supposition in the arena of personalized genomics. Nat Genet 2008;40: 939-942.

118 Syurina EV, Brankovic I, Probst-Hensch N, Brand A: Genome-based health literacy: a new challenge for public health genomics. Public Health Genomics 2011;14:201-210.

119 Vassy JL, O’Brien KE, Waxler JL, et al: Impact of literacy and numeracy on motivation for behavior change after diabetes genetic risk testing. Med Decis Making 2012;32: 606-615.

120 Marteau TM, French DP, Griffin SJ, et al: Effects of communicating DNA-based disease risk estimates on risk-reducing behaviours. Cochrane Database Syst Rev 2010;10: CD007275.

121 Grant RW, O’Brien KE, Waxler JL, et al: Personalized genetic risk counseling to motivate diabetes prevention: a randomized trial. Diabetes Care 2013;36:13-19.

122 Faith MS, Pietrobelli A, Heo M, et al: A twin study of self-regulatory eating in early childhood: estimates of genetic and environmental influence, and measurement considerations. Int J Obes (Lond) 2012;36:931-937.

123 Silventoinen K, Rokholm B, Kaprio J, Sorensen TI: The genetic and environmental influences on childhood obesity: a systematic review of twin and adoption studies. Int J Obes (Lond) 2010;34:29-40. 